\title{
Research on the training mode of college-enterprise cooperation for part-time Postgraduates
}

\author{
Xiaoyong Liu a and Hui Fu* \\ Guangdong Polytechnic Normal University, Guangzhou, Guangdong, 510665, China \\ axyong420@126.com, blindafh819@126.com
}

Keywords: The integration of industry and education, College-enterprise cooperation, Postgraduate education.

\begin{abstract}
The integration of industry and education refers to the deep cooperation between application-oriented universities and enterprises or between vocational colleges and enterprises in order to improve the quality of personnel training, whose contents include universities and enterprises docking, specialties and industrial docking, course content and occupation standard docking, teaching process and the production process of docking. College-enterprise cooperation is an important way of integration of industry and education. In order to improve the quality of personnel training, it is necessary to pay more attention to the deep cooperation between college and enterprise in the training of part-time postgraduates. But from the current situation of postgraduate training in China, there are still many problems in college-enterprise cooperation. This paper mainly discusses the current situation and existing problems of college-enterprise cooperation for part-time postgraduates.
\end{abstract}

\section{Introduction}

Part-time postgraduates in Vocational colleges (hereinafter referred to as "master of Vocational Education") is an occupation degree for teachers of the medium occupation school, which belongs to the category of professional degree education, aimed to cultivate the Academic-practical Teachers, which have profound professional theory and have the occupation skills of high-quality and professional skills. Therefore, practical ability is an important training objective of master of Vocational Education[1,2].

The secondary occupation education is an important part of China's occupation education, vigorously develop secondary occupation education is to speed up the popularization of high school education, improve the comprehensive quality of the whole nation cultural knowledge, practical skills and innovation ability, basic engineering construction of Army force conveying national industry; is an important way to promote employment and improve people's livelihood is the key link; to ease the contradiction of labor force structure. In recent years, the Central Committee of the CPC and the State Council have implemented a series of major measures to continuously improve the policy environment, institutional environment and social environment, and promote the reform and development of secondary vocational education to achieve historic success. In 2009 to start the implementation of the secondary occupation education tuition free policy, the important position of secondary occupation education in the overall economic and social development and education in the overall situation is more prominent, the reform and development of secondary occupation education ushered in the great opportunity of hitherto unknown. Under such circumstances, the development level of vocational education depends largely on whether there is a high quality, high skilled, high-level, professional teacher team. Therefore, the exploration and practice of master innovation practice ability of vocational education training mode, strengthen vocational education master's ability of innovation and practice, so as to improve the overall quality of the contingent of teachers in 
secondary vocational schools in our province and level, and improve the teaching quality and the teaching level of vocational education has a good significance.

This paper first introduces the research status of school enterprise cooperation training, and then explores some problems existing in school enterprise cooperation, and finally puts forward the idea of problem solving.

\section{Research statuses}

\section{Training mode of college-enterprise cooperation in China.}

Compared with the some developed countries, our country started late in the theory and practice of the cooperation between schools and enterprises[3]. But in the past ten years, with the continuous and rapid development of China's social economy, the training of school enterprise cooperation has also made considerable progress[4]. Many domestic experts and scholars have carried on the thorough discussion to the school enterprise cooperation training pattern. In the existing research, according to the dominant role in the process of school enterprise cooperation, the school enterprise cooperation can be divided into the following basic modes: Government-Orientation type, Enterprise-Orientation type and College-Orientation type.

The Government-Orientation type of cooperation between school and enterprise refers to a cooperation mode led by the government in the composition and operation of school enterprise cooperation[5]. In the planned economy period from 1949 to 1978, government directives were adopted. In order to promote the rapid development of science and technology, developing heavy industry, especially the construction of Chinese of national defense science and technology, Chinese government direct instruction in universities and research institutions, universities and enterprises to cooperate to overcome technical problems, and develop corresponding personnel. In the school enterprise cooperation in recent years, the government plays a major role in promoting, that is, the government to promote the model. The government set up a platform for the cooperation between universities and enterprises, and also provides policy support for cooperation, or government funded on school enterprise cooperation training and scientific research investment; provide cutting-edge technology and talent needed for social and economic development.

Enterprise-Orientation type refers to the cooperation in the training process, the enterprise according to their own needs, talent and technology, with the cultivation of talents and technology development with universities, in this process, the main business is the leading role in training talents, but also the main research activities. Is the enterprise oriented school enterprise cooperation training advantage: enterprises are familiar with the market, familiar with the direction of social and economic development, as soon as possible to understand the development of enterprises need what kind of talent and technology; at the same time, enterprises with advanced equipment and abundant capital, for personnel training and scientific research activities to provide a solid foundation. But it also has shortcomings: compared with universities, enterprises lack a high level of $\mathrm{R} \& \mathrm{D}$ personnel, the investment in scientific research is relatively small, the enterprise independent innovation ability is weak; influenced by foreign advanced technology, the current Chinese the dependence on foreign technology is high, some enterprises to invest on independent research and development, the lack of enterprise dynamic cooperation.

The College-Orientation type, just in the cooperation process, to colleges and universities as the main body, in order to improve their teaching quality and teaching level, provide innovative talents for the society, cooperation research and talents training and enterprises. Colleges and universities can make use of the advantages of enterprises in the aspects of capital and equipment to realize their own scientific research, and transfer scientific research results to enterprises, and realize the goal of talent training in this process.

\section{Training mode of college-enterprise cooperation in other countries [6,7].}

The United States is the first country of cooperation, in a sense the history of the development of modern America is a history of cooperation, the United States in order to maintain and strengthen their competitive advantage, need continuous technological innovation, and these technologies must 
be effectively transformed into commodities, the United States has been since the school enterprise cooperation and attention. In the United States, with the development of science and technology, the relationship between colleges and enterprises is becoming closer and closer, and high-tech industrial clusters are beginning to form. For the high-tech industry, and the cooperation of universities can provide talents to adapt to their own production and development for it; for colleges and universities, and enterprise cooperation can provide a wide range of funds and financial support for University Graduate education. In 1950, the Stanford University created a new model of graduate school enterprise cooperation. In 1994, the United States government promulgated "science for the development of national interests", which requires graduate training objectives and national development strategy and objectives are consistent. After that, the cooperation between universities and enterprises started, and the training mode of graduate school enterprise cooperation came into being. Universities and enterprises jointly put forward research topics, while conducting common research and exploration, research results can be used to improve the level of technology and innovation of enterprises.

Japanese industry university research cooperation is called "government industry university research", which shows that the Japanese government plays a leading role in the school enterprise cooperation in japan. The government plays a guiding and promoting role in the industrialization of science and technology through the formulation of corresponding policies and regulations. In 1956, Japan began to implement "education system"; in 1958, the Japanese government established the principal research system, encourage enterprises to entrust the universities or research institutions for research and development, and set up a corresponding system in Colleges and universities, on behalf of enterprises, cultivate high-level talents for its development; in 1981, Japan has established the cooperative system, and after 1990s, the cooperation as a basic national policy of Japan, and the establishment of the relevant organization. In recent years, Japan's cooperation have been further developed, the government put the cooperation between universities and enterprises as an important means to realize the reorganization of social economic structure and reform, and take a number of incentives to motivate and guide the cooperation, hoping to achieve the technological innovation of enterprises, make a breakthrough in New Technology in Japan the field, and can get long-term development.

\section{Problems in college-enterprise cooperation}

\section{Not clear of the property rights relationship between college and enterprise.}

In graduate school enterprise cooperation, property rights relationship mainly refers to the ownership of scientific research achievements and interests in the cooperation between the two sides. At present, the domestic graduate school enterprise cooperation is still in the stage of continuous development, theory and practice are not mature enough. Therefore, there is no clear understanding of the ownership of property rights in graduate school enterprise cooperation. Both schools and enterprises emphasize the ownership of research achievements based on their own needs. In this case, the relationship between property rights in school enterprise cooperation is not clear, it will inevitably cause disputes arising from competition. In the school enterprise cooperation, the unclear property rights relationship can easily affect the enthusiasm of school enterprise cooperation, and become an important obstacle to restrict the training of graduate school enterprise cooperation.

\section{Lack of evaluation criteria and evaluation system}

At present, the domestic graduate school enterprise cooperation training lacks the corresponding evaluation standards and evaluation system. School enterprise cooperation postgraduate training management level, how the system is perfect, the curriculum and the practice arrangement is reasonable, how the final results, the two sides have little cooperation to establish a system of standards to measure. The evaluation standards and evaluation system is to evaluate and assess the personnel training process and final results of school enterprise cooperation scientifically and rationally, and ensure the cooperation development can be closer to the goal of cooperation between the two sides. In the mode of training graduate students in school enterprise cooperation, the focus of 
evaluation should be placed in the curriculum, practical arrangements, research results and work ability. At the same time, the center should be transferred from universities to society and enterprises. To a great extent, the evaluation criteria are in line with the need of social development for technological development and application, and whether it meets the needs of human capital in socio-economic development.

\section{Lack of cooperation and innovation power between school and enterprise}

At present, the domestic graduate school enterprise cooperation to train the lack of power, this is because both sides are excessively concerned with their own short-term interests, because cooperation need to invest a certain amount of manpower, financial and material resources, so the two sides are afraid to throw the motivation after The loss outweighs the gain., lack of school enterprise cooperation. Or cooperation, but the effect is not good, did not achieve the desired results of scientific research innovation. Even pure technological innovation can cause innovation failure because of poor management in the process of cooperation. The main body of graduate school enterprise cooperation is university and enterprise, belonging to different organizations, so the structure, principle and mechanism of the organization are very different. Cooperation between the two sides of the cooperation organization don't meet the expected demand, both for cognitive cooperative target is not uniform, the staff do not match, the lack of incentive and supervision is not in place, poor communication and management ability, is a major obstacle to postgraduate training cooperation.

\section{Conclusions}

To improve the ability of independent innovation needs, training mode of school enterprise cooperation is popular at present, both universities and enterprises can play their respective advantages in resources, but also to cultivate innovative for economic and social development and the needs of innovation of high-level talents, this is one of the universities and enterprises to achieve win-win model. In the integration of production and education under the guidance of the concept, strengthen the cooperation between universities and enterprises, so that enterprises in the production of teaching and combined with each other, both sides support each other, complementary advantages, mutual involvement, sharing of resources, is to realize the modernization of management, talents training and enterprises to promote the development of productive forces, an important way to achieve education and production sustainable development[8]. Thus, the combination of production, teaching and research is an effective means to promote personnel training, scientific and technological innovation and economic and social development. The personnel training mode of school enterprise cooperation is an important way to improve the level of education, promote the ability of independent innovation, and train the talents needed for the rapid development of economic society. On the cultivation of students, you can better grasp the direction of social and economic development, cultivate high-level innovative talents of the social development and needs, and improve the level of scientific research; to master graduate student of vocational education itself, one can accept the high school academic culture tradition, expand the horizons of knowledge, learning to the field of cutting-edge technology, on the other hand can improve their practice and adapt to the needs of vocational education competitiveness, cultivate their scientific research ability and the ability of innovation and practice, so as to improve the level of their business.

\section{Acknowledgements}

This work has been supported by grants from Graduate innovation program of Guangdong Province(2016JGXM_MS_48), Teaching quality and teaching reform projects of Guangdong Province in 2015 (Comprehensive Reform Project of Information and Computer Technology Specialty in Colleges and Universities); Teaching research and reform project of higher education of Guangdong Province in 2015 (Research and Practice of Co-cultivation Mode of Interdisciplinary Talents in Information and Computer Technology Specialty), Teaching research and reform project of higher education of Guangdong Province in 2014 (Research on students' independent innovation 
practice ability based on problem-based learning and project-based learning) and Guangdong Vocational Colleges Teacher Training Project in 2017. The authors are partly supported by Guangdong science and technology project (NO. 2016A070713004, No. 2017A040403068), Guangdong Natural Science Foundation (NO.2015A030313664).

\section{References}

[1] Nianyou Chen, Changqing Zhou, Zhuping Wu. Connotation and implementation of integration of industry and education. Chinese University Science \& Technology, 2014, (08): 40-42.

[2] Tianyu Yu, Ye Cao. Research on the status, problems and Countermeasures of secondary vocational school teachers studying for master's degree. Chinese Vocational and Technical Education, 2013, (24): 31-38.

[3] Cihui Xu, Zhihua Bao, Guoqing Wu, etl. Practice and exploration of talent cultivation mode of university industry cooperation graduate student. Industrial \& Science Tribune, 2013,12 (21): 209-211.

[4] Yue He, Wei Zhang, Yi Zheng. Exploring the interdisciplinary training model of graduate students. Journal of National Academy of Education Administration, 2011, (07): 31-34.

[5] Guanghua Shao.Study on the practical teaching mode of full time master of education in professional degree. Teacher Education Research, 2012,24 (02): 87-91,47.

[6] Wentao Huang, Xuezeng Zhao. Review and Enlightenment of foreign postgraduate training model. Journal of Graduate Education, 2013, (03): 87-90

[7] Ruiwen He, Yuenan Zeng, Yun Xie. Research on the inter school cooperation mechanism of graduate education and its implementation in university town. China Electric Power Education, 2013, (29): 12-13,27

[8] Xiang Wang. Research on training mechanism and strategy of school enterprise cooperation for graduate students. University of Jinan, 2011. 